\title{
A Discrete Choice Experiment to Explore Carer Preferences
}

Helen Chester

Personal Social Services Research Unit (PSSRU)

University of Manchester

Paul Clarkson

Personal Social Services Research Unit (PSSRU)

University of Manchester

Linda Davies

Manchester Centre for Health Economics, University of Manchester

Caroline Sutcliffe

Personal Social Services Research Unit (PSSRU)

University of Manchester

Brenda Roe

Evidence-based Practice Research Centre, Edge Hill University/Personal Social Services Research Unit (PSSRU), University of Manchester

Jane Hughes

Personal Social Services Research Unit (PSSRU)

University of Manchester

David Challis

Personal Social Services Research Unit (PSSRU)

University of Manchester

Corresponding author: Helen Chester; helen.chester@manchester.ac.uk 


\section{Biographical details:}

Helen Chester is a Research Associate at the PSSRU, University of Manchester. Her work currently involves research relating to the provision of services for supporting vulnerable older people including those with dementia, employing both primary and secondary data analysis. She has worked on a range of studies of commissioning services, dementia care, and assessment of needs.

Paul Clarkson is Research Fellow, PSSRU, University of Manchester. Formerly a psychiatric and medical social worker he has undertaken research in community mental health, primary care and social care. He has previously worked on research and demonstration projects in collaboration with university researchers in Japan, the US, Canada and Northern Ireland. His current activities involve research on different models of home support to people with dementia and their carers.

Linda Davies is Professor of Health Economics at the Manchester Centre for Health Economics, University of Manchester. Her key research interests are the economic evaluation of complex interventions for people with complex needs and valuation of preferences for alternative interventions and outcomes.

Caroline Sutcliffe is a Research Associate with a psychology background. Her research interests encompass a broad area of study including residential and nursing home care, health and community care of older people with mental health problems and people with dementia and their carers.

Brenda Roe is Professor of Health Research at the Evidence-based Practice Research Centre, Edge Hill University and Honorary Fellow at PSSRU, University of Manchester. Her work focuses on evidence synthesis and mixed methods studies relating to older people with long term conditions and carers in the community and care homes and at end of life.

Jane Hughes is a Lecturer in Community Care Research at the PSSRU, University of Manchester and a registered social worker. Currently her principal research activities are centred on services for vulnerable older people at home.

David Challis is Professor of Community Care Research and Director of PSSRU, University of Manchester, and Associate Director of the NIHR School for Social Care Research. He has undertaken the development and evaluation of a series of studies of community based care for older people which provided alternatives to hospital and nursing home care; national studies of care coordination in older people's services; evaluations of assessment procedures in England; and a range of studies on the mental health of older people.

\section{Acknowledgements:}

This work was commissioned and funded by the Department of Health to inform the implementation of the National Dementia Strategy and supported by the Association of Directors of Adult Social Services. We are most grateful to the carers who participated in the study and the voluntary organisations who facilitated this. Responsibility for the article is ours alone. The views expressed are those of the authors and not necessarily those of the NHS, local authorities, the NIHR or the Department of Health. 


\begin{abstract}
Purpose

This paper describes a case study to test the applicability of the Discrete Choice Experiment (DCE) method to assess the preferences of carers of people with dementia. The focus of enquiry was home care provision.
\end{abstract}

Design/methodology/approach

A multi-method approach was adopted for this pilot study. A literature review identified key characteristics of home care for dementia. This informed consultations with lay representatives. Key attributes of home care for the DCE were identified and formed the basis for the schedule. Twenty-eight carers were recruited by two voluntary organisations to complete the DCE. A multinomial logistic regression model was used to analyse the data.

\title{
Findings
}

Seven attributes of home care for people with dementia were identified from the consultation. Use of the DCE approach permitted the identification of those most important to carers. Despite the modest sample, statistically significant findings were reported in relation to five of the attributes indicating their relevance. Lay involvement in the identification of attributes contributed to the ease of administration of the schedule and relevance of the findings.

\section{Originality/value}

This study demonstrated the utility of a DCE to capture the preferences of carers of people with dementia and thereby gather information from carers to inform policy, practice and service development. Their involvement in the design of the schedule was critical to this process.

\section{Introduction}


Dementia is a major cause of disability and high cost care in older people and thus has represented a significant public health and care challenge, globally for many years (Ferri et al., 2005). In England, most (two-thirds) people with dementia live at home supported by family carers and National Health Service, local authority and voluntary organisations (Department of Health, 2013). Evidence suggests that specialist services for older people with dementia are under-developed in comparison with services for older people generally (McDonald and Heath, 2008). Moreover, there is a paucity of evidence about user preferences for different forms of home care support, particularly support to carers of people with dementia (Newbronner et al., 2013).

A central aim of the National Dementia Strategy in England was to help people to 'live well' with dementia by providing assistance with daily living to enhance their well-being (Department of Health, 2009). This requires the provision of effective and appropriate support for people with dementia and their carers at home. The study described below, was one of five designed to provide guidance to those responsible for commissioning and delivering home care services informing the implementation of the strategy, within a short timeframe (Department of Health, 2009 -objective 6). Its focus was to explore the relative merit of specialist home care provision exclusively for older people with dementia compared with generic home care services available to all vulnerable older people (Challis et al., 2011). In this paper the aim is to describe the study which investigated the preferences of carers and to reflect on the use of the Discrete Choice Experiment (DCE) with this group of people. To achieve this, and in contrast to the guidance which is publicly available, the full methodology and detailed findings are presented, the latter providing a means of evaluating the former.

DCEs permit an individual to select, for instance, their preferred service according to its different characteristics or attributes at varying levels of provision and therefore provide a 
means of eliciting patients' preferences for particular attributes of health care (Ryan et al., 2001). In this example, a DCE includes a series of choice questions. In each, respondents are asked to choose between descriptions of two or more hypothetical services. The same attributes are used to describe each service, across all the choice sets. However, the levels of attributes differ between choices. It is assumed that individuals are prepared to trade off one attribute against another. Using fixed attributes, but varying levels, over a series of choices, means it is possible to estimate respondents' strength of preference for the different attributes of a service.

For carers, DCEs offer the opportunity to make more realistic choices as compared with simple ranking exercises, which ask them to assess features separately rather than as part of a package of care. Separate choices may oversimplify the situation compared with options carers face in real world situations. DCEs are also sensitive to changing levels of input rather than just the presence or absence of features and thus enables the prioritisation of differing degrees of input and allows the researcher for example to ascertain whether a small amount of an attribute is enough to satisfy carers. However, there have been limited previous applications in social care (Hall et al., 2007; Ryan et al., 2006; Nieboer et al., 2010). In this study, the approach was used to explore informal carers' preferences for different attributes of home care for older people with dementia.

\section{The research process}


There were two sequential steps in this pilot project: the design of the schedule and the collection and analysis of the data.

\section{Schedule design}

The four stages to developing the interview schedule are described below. This included a literature review and lay consultation to inform the identification of the attributes and formulation of levels within the attributes thereby promoting transparency in the process (Coast and Horrocks, 2007).

Identification of characteristics of home care: The range of characteristics of home care services for dementia that may be important to people with dementia and their carers was identified through one of the five studies commissioned to provide guidance to service commissioners. This was a purposive literature review which included evidence of specialist and generic domiciliary care services for older people with dementia (Challis et al., 2010). Characteristics and themes for discussion with key actors in their decisions to use, provide, and commission home care services, were generated from this.

Devising the attributes: The salient characteristics of home care services considered important for people with dementia were identified through two consultation meetings. Seven different participants, purposively selected, attended each and they comprised carers, carer representatives, voluntary sector providers and local authority commissioners. They were presented with the list of characteristics identified from the literature review. Attendees were asked to prioritise these and state their views as to whether they were meaningful and had salience to them in their respective roles. These characteristics were then used by researchers to inform the range of attributes used for the DCE. 
Selecting the attributes: Eight were selected by the consultation groups and one was rejected by the research team because of the requirement for attributes to be mutually exclusive and capable of being traded off (Coast and Horrocks, 2007). Two of the seven remaining attributes were service costs and waiting times. These were used in the DCE as an indirect method of estimating willingness to pay or wait for each attribute. Real unit costs of home care in England were used to inform both the budget example and the levels of the cost attribute (Knapp et al., 2007). The remaining five comprised a mix of service components (use of life story or memory wallets; respite opportunities for carers) and characteristics of care workers (home care worker availability; continuity of care worker in terms of the home care worker visiting being the same person each time; home care workers training in dementia care) and are described in Table I.

\section{[insert Table I around here]}

Formulating the choice questions: In this study each choice question employed attributes to describe two different hypothetical home care packages (option A or option B) and asked respondents to choose the one they preferred most. The terminology employed and the description of the levels was informed by the consultation groups. The same attributes were used in each choice question. However, the levels of the attributes varied between each hypothetical home care package. Details of the different levels of each attribute are described in Table II including those relating to cost and waiting time. These were constructed to describe different home care packages and clearly distinguish between them.

[insert Table II around here] 
Figure I provides an example of one of the eighteen choice questions included in the DCE schedule. It was not possible to include all possible combinations of attributes and levels in this. Accordingly, a fractional factorial design was used to select the combination of attribute levels that allows all effects of interest to be estimated (Burgess, 2007; Ryan et al., 2001) [1].

\section{[insert Figure I around here]}

\section{Data collection and analysis}

Three meetings were convened by Age UK organisations in the North West of England in June 2010. Attendees were carers of people with dementia who had received home care services. The actual number of carers attending the sessions was dependent on their other commitments. Venues were accessible and familiar to participants and refreshments were available. An explanation of the DCE was given at the start of each session with large print examples provided. In each of the three groups, participants completed the schedule in a relaxed setting, where they were able to chat informally to others, including the researchers. All participants successfully completed the schedule requiring little assistance and offered voluntary feedback throughout as well as in a structured discussion at the end of the session. Data from the completed paper schedules was entered and prepared for analysis using SPSS version 20 and analysed using the statistical package STATA. There were multiple observations for each respondent, reflecting the number of choice questions in the DCE design. A model was estimated to ascertain the relative importance of each attribute in the choice of care package. The probability of each respondent in the sample choosing A or B for each choice was dependent on the seven attributes included [2]. The full model is reported with all attributes included irrespective of statistical significance. This approach was chosen because of the small 
sample size, due to it being a pilot project, and because of the possibility that non-significant attributes may still have influenced respondents' choices. Furthermore, it facilitated the evaluation of the methodology. Due to the insignificance of the cost and waiting time variables, it was not possible to calculate marginal willingness to pay and wait values (Nieboer et al., 2010).

\section{Results}

Twenty-eight carers completed the questionnaires and on average this took between 35 and 40 minutes. Their average age was 66 years of age. Three-quarters ( 75 per cent) were female and most (96 per cent) were of white British ethnic origin; around two-fifths (39 per cent) were retired with nearly a quarter ( 24 per cent) engaged in paid work.

\section{Interpretation of carer preferences}

Table III presents the findings from the analysis which explored the influence of each attribute on respondent choices between alternative care packages. The coefficients from the model are examined to explore the strength and significance of each attribute.

\section{[insert Table III around here]}

The model provides information about the direction of the influence of each attribute, for example a positive sign for the 'the home care worker visiting - is the same person each time' attribute indicates that a service with this feature will be preferred to one without this feature. Carers judged this to be one of the most important attributes together with the home care worker 
having some or full additional training in the care of older people with dementia. The results indicated that respondents preferred the home worker visiting them to be the 'same person each time' or to 'vary from time to time' to them being a 'different person each time.' The coefficient for the 'same person each time' $(\beta=0.696, p=0.000)$ is nearly three times that of 'varies from time to time' $(\beta=0.245, p=0.081)$, indicating a greater preference for this (everything else held equal). The positive and significant coefficients on 'some training' and 'full training' in relation to training in dementia care indicated that respondents prefer home care workers to have received additional training in dementia care. The coefficients for 'some training' $(\beta=0.650, p=0.000)$ and 'full training' $(\beta=0.661, p=0.000)$ are similar, implying that (all else equal) there was little difference in respondents' preferences in this regard. Findings also indicated carers preferred a service where there was full use of life story or memory wallets $(\beta=0.263, p=0.056)$ compared to one where these were only partially used $(\beta=0.149, p=0.287)$ or not used at all (base category). Also indicated was a preference for home care workers being available at the weekends $(\beta=0.314, p=0.023)$ and some form of respite service being provided for carers (limited respite service $(\beta=0.357, p=0.010)$; full respite service $(\beta=0.468, p=0.001)$. Cost $(\beta=0.003, p=0.210)$ and waiting time $(\beta=-0.016, p=0.240)$ were not significant influences.

\section{Carer views of the approach to data collection}

Participants were asked for feedback on the DCE. Participants requested clarification of terminology relating to two of the attributes: 'home care workers use life story or memory wallets' and 'respite opportunities for carers.' With regard to the former, the request was for an explanation of what life story or memory wallets comprised and with regard to the latter, the parameters of respite care - duration (day time or overnight) and location (in their own 
home or in a care home) were explained. Feedback from the groups was positive overall. Participants generally understood the researchers' explanation of the attributes and with a clear explanation of the process carers were able to complete the exercise. They were complimentary about the task and although they found it unusual (as it involved hypothetical scenarios that some had not experienced), they enjoyed the intellectual stimulation it provided them with.

\section{Discussion}

In this paper, we reflect on the appropriateness of a DCE to explore carers' preferences for home care for people with dementia through presentation of a full description of the methodology and detailed findings. However, it is important to note that this was a pilot study, undertaken in a short timeframe, with a modest sample size. This may have contributed to the insignificance of the attributes in the model, including cost. In a larger sample, these attributes may have been found to have a significant impact on respondents' choices. Moreover, the sample represented 'enthusiasts,' those willing to participate in the research. Of particular note, was the proportion of carers who were in employment, suggesting that both spousal and intergenerational carers were included in the sample. Notable absentees however are those prevented from participating by virtue of their full-time caring responsibilities. Furthermore, whilst carers were consulted about the attributes explored in the DCE, inevitably the technique necessitates that only a subset can be included. Nevertheless, within these limitations, the study does offer credible evidence of the value carers place on different aspects of home care and the feasibility of using this technique to explore this. The principal findings from this study are discussed in relation to the involvement of lay representatives in design; the development of the attributes for inclusion in the DCE; and arrangements for data collection. 
Public involvement in research is recognised as integral to the process (Davies, 2009). With regard to the conduct of research, nine stages have been identified, with varying 'options' for consumer involvement at each stage. This article describes an example of coproduction within the research process in which two lay consultation groups were integral to the design phase (Hanley et al., 2004). In this context coproduction was defined as an active partnership between key stakeholders - interested citizens by virtue of their experience and knowledge of service use - and the researchers. It was predicated on the assumption that this would make the study more effective and credible (Davies, 2009).

In this study, the key stakeholders (lay representatives) collaborated with researchers to develop the attributes (Hanley et al., 2004). The benefits of this approach were that it increased the likelihood that the attributes were relevant to those completing the DCE. Evidence for this was demonstrated by the ease by which the schedules were completed and the significance of the findings. It has been suggested elsewhere that the approach adopted has to be commensurate with the area of enquiry and the topic under investigation (Coast and Horrocks, 2007). However, it is important to ensure that the key stakeholders and researchers involved in the schedule design have detailed knowledge of the subject under investigation - in this study home care for older people with moderate/severe dementia. Carers' preferences and priorities may change over time and over the course of the condition so it is important to take this into account when designing research (Nurock and Wojciechowska, 2007). It was ensured that the focus was specifically only upon carers of people with moderate/severe dementia. Subsequent research by the authors has also focused on people with moderate/severe dementia and their carers separately from similar enquiry regarding those in early stage dementia, to ensure the development and selection of attributes are relevant and appropriate to different stages of the condition. In this pilot study, an important factor was the timescale available for completion. 
If more time had been available there would have been the opportunity for a wider consultation on the composition of the attributes with the possibility of including people with dementia.

\section{Development of attributes}

In the construction of DCEs the researcher is restricted in the number of attributes that can be included because of a limit on the amount of information people can process. If too many attributes are included, participants can find it tiring, leading them to ignore attributes or address them in random ways (Green and Srinivasan, 1990). This is a general limitation with DCEs. In this study, the selection of attributes was undertaken in conjunction with a heterogeneous group of key stakeholders and lay representatives, including carers and commissioners of home care services. Consultation meetings were undertaken prior to and during the development of the DCE, complementing the literature review, to facilitate the development of a relevant and user-friendly schedule. This provided useful validation of attributes for inclusion in the exercise and helped ensure they had real world validity (Turner et al., 2007). Undertaking such research to inform attribute and level selection is very appropriate when using this technique and often neglected by researchers conducting DCEs (Clark et al., 2014). Evidence of the importance of investing such time in the development of attributes for the DCE comes from feedback from the participants about the schedule and the completion rate. Furthermore, the value of investing time in the development of the attributes was evident in the significance of many of the attributes in the context of the small sample size (Coast and Horrocks, 2007).

\section{Administration of the schedule}

Overall, the completion of DCEs is considered to be cognitively demanding, yet carers in this study appeared to enjoy the challenge (Bryan and Dolan, 2004). All carers who attended the meetings successfully completed the schedule. The format of the data collection arrangements 
that permitted time for informal group discussion and debriefing after completion of the schedule provided the opportunity for carers to provide further information about their experience of home care support. In retrospect it would have been worth considering collecting this data more systematically by utilising a focus group methodology alongside the completion of the DCE schedule. Focus groups have been described as unstructured interviews with small groups of people who interact with each other and the group leader using group dynamics to stimulate discussion, gain insights and generate ideas in order to pursue a topic in greater depth, particularly issues associated with service development and evaluation (Bowling, 1997; Merton and Kendall, 1946). Group processes can help people to explore their views and generate questions in ways they would find more difficult in face-to-face interviews (Kitzinger, 1995). This would have contributed to a mixed-methods study with the advantage of the richness and diversity of personal experiences being reported alongside the structured findings from the DCE thereby increasing the utility of the findings overall.

\section{Conclusion}

The aim of this paper was to describe the study which investigated the views of carers and reflect on the use of the Discrete Choice Experiment (DCE) with this group of people. It is concluded that DCEs provide a useful and feasible means of identifying aspects of home care important to carers of people with dementia. As noted in the introduction, DCEs provide an opportunity to systematically canvas views and those concerning what care was needed, and priorities for different components have been seen as increasingly important (Freeman and Hughes, 2010; Care Quality Commission, 2013). This is important because patient and carer preferences can guide treatment and care options and more generally service development. Recognising and responding to stated preferences are part of promoting person-centred care, associated with better engagement with treatment and care options (Wilberforce et al., 2016). 
Integral to this conclusion is the investment of time and expertise in the development of the interview schedule. It was important to involve carers and others knowledgeable about home care services in its development to ensure its relevance and utility. An additional observation was that the value of DCE findings might be supported through their inclusion within a mixedmethods study, permitting findings to be complemented, exemplified, illustrated and verified through reference to insights gained from qualitative discussions of personal experiences and thought processes.

\section{Notes}

[1] Published design catalogues were used to identify the levels for option $\mathrm{A}$ in each choice set. Modulo arithmetic was used to determine the levels for option B (Sloane, 2010; Burgess, 2007). This ensured that, for each attribute in each choice set, the levels in service options A and $\mathrm{B}$ were different. The design of the choice questions met published criteria so that each level appears with equal frequency (level balance), there was no overlap between attribute levels in each choice set, efficiency and near orthogonality (attributes were statistically independent and uncorrelated).

[2] A multinomial logit model (conditional logit model), an approach widely used in applications of this nature, was used to analyse the data and estimate the weights (Ryan et al., 2008; Bowen et al., 2012). A logit model with random effects was also estimated which gave similar results. The model was statistically significant but a low Rho statistic indicated no significant unobserved correlations over responses from each person, indicating a random 
effects model was not required (Gerard et al., 2008) and thus it was considered that the conditional logit model was sufficient for this analysis.

\section{References}

Alzheimer Scotland (2008), Meeting our needs? - the level and quality of dementia support services in Scotland, Alzheimer Scotland, Edinburgh.

Bamford, C. and Bruce, E. (2000), "Defining the outcomes of community care: the perspectives of older people with dementia and their carers", Ageing and Society, Vol. 20, No. 5, pp. 543570.

Bourgeois, M. (2013), Memory Books and Communication Aids for People with Dementia, Health Professions Press Inc., Maryland US.

Bowen, A., Hesketh, A., Patchick, E., Young, A., Davies, L., Vail, A., Long, A., Watkins, C., Wilkinson, M., Pearl, G., Lambon Ralph, M. and Tyrrell, P. (2012), Clinical effectiveness, cost-effectiveness and service users' perceptions of early, well-resourced communication therapy following a stroke: a randomised controlled trial (the ACT NoW Study). Health Technology Assessment 2012; Vol. 16, No. 26, pp. 1-160.

Bowling, A. (1997), Research Methods in Health Investigating Health and Health Services, Open University Press, Buckingham. 
Bryan, S. and Dolan P. (2004), "Discrete choice experiments in health economics: for better or for worse?", European Journal of Health Economics, Vol. 5, No. 3, pp. 199-202.

Burgess, L. (2007), Discrete choice experiments [computer software], Department of Mathematical Sciences, University of Technology, Sydney, http://crsu.science.uts.edu.au/choice/.

Care Quality Commission. (2013), Not Just a Number: Home Care Inspection Programme. National Overview. Care Quality Commission, Newcastle upon Tyne.

Challis, D., Sutcliffe, C., Hughes, J., von Abendorff, R., Brown, P., and Chesterman, J. (2009), Supporting People with Dementia at Home: Challenges and Opportunities for the $21^{\text {st }}$ Century, Ashgate, Surrey.

Challis, D., Clarkson, P., Hughes, J; Chester, H., Davies, S., Sutcliffe, C., Xie, C., Abendstern, M., Jasper, R., Jolley, D., Roe, B., Tucker, S. and Wilberforce, W. (2010), Community Support Services for People with Dementia: The Relative Costs and Benefits of Specialist and Generic Domiciliary Care Services, Discussion Paper M245-3, PSSRU, University of Manchester, Manchester.

Challis, D., Clarkson, P., Hughes, J; Chester, H., Davies, S., Sutcliffe, C., Xie, C., Abendstern, M., Jasper, R., Jolley, D., Roe, B., Tucker, S. and Wilberforce, W. (2011), Community Support Services for People with Dementia: The Relative Costs and Benefits of Specialist and Generic Domiciliary Care Services, http://sites.nursing.manchester.ac.uk/pssru/research/nihrsscr/productsandtoolkits/Community SupportServicesforPeoplewithDementia.pdf, accessed 24 ${ }^{\text {th }}$ April 2015. 
Clark, MD., Determann, D., Petrou, S., Moro, D. and De Bekker-Grob EW. (2014), Discrete Choice Experiments in health economics: a review of the literature. Pharmacoeconomics, Vol. 32, No. 9, pp.883-902.

Coast, J. and Horrocks, S. (2007), "Developing attributes and levels for discrete choice experiments using qualitative methods," Journal of Health Services Research and Policy, Vol. 12, No. 1, pp.25-30.

Davies, S. (2009), "Foreword", in Staley, K. (Ed.), Exploring Impact: Public Involvement in NHS, Public Health and Social Care Research, INVOLVE, Eastleigh, pp. 4-5.

Department of Health (2009), Living Well with Dementia: A National Dementia Strategy, Department of Health, London.

Department of Health (2013), Dementia: A State of the Nation Report on Dementia Care and Support in England, Department of Health, London.

Featherstone, K., James, I., Powell I., Milne, D. and Maddison, C. (2004), “A controlled evaluation of a training course for staff who work with people with dementia", Dementia, Vol. 3, No. 2, pp. 181-94.

Ferri, C., Prince, M. and Brayne, C., Brodaty, H., Fratiglioni, L., Ganguli, M., Hall, K., Hasegawa, K., Hendrie, H., Huang, Y., Jorm, A., Mathers, C., Menezes, P., Rimmer, E. and 
Scazufca, M. (2005), "Global prevalence of dementia: a Delphi consensus study", The Lancet, Vol. 366, No. 9503, pp. 2112-2117.

Freeman, G. and Hughes, J. (2010), Continuity of Care and the Patient Experience. The King's Fund, London.

Gerard, K., Shanahan, M., and Louviere, J. (2008), "Using discrete choice modelling to investigate breast screening participation” in Ryan, M., Gerard, K., and Amaya-Amaya, M. (2008) (eds). Using discrete choice experiments to value health and health care. Springer, New York, NY.

Green, P. and Srinivasan, V. (1990), “Conjoint analysis in marketing: new developments with implications for research and practice", Journal of Marketing, Vol. 54, No. 4, pp. 3-19.

Hall, J., Kenny, P. and Hossain, I. (2007), The provision of informal care in terminal illness: an analysis of carers' needs using a discrete choice experiment. CHERE Working Paper 2007/12. Centre for Health Economics Research and Evaluation Faculty of Business University of Technology, Sydney.

Hanley B., Bradburn J., Barnes, M., Evans, C., Goodare, H., Kelson, M., Kent, A., Oliver, S., Thomas, S. and Wallcraft, J. (2004), Involving the Public in NHS, Public Health, and Social Care Research: Briefing Notes for Researchers. Second Edition edited by Roger Steel, INVOLVE, Hampshire. 
Hoerster, L., Hickey, E. and Bourgeois, M. (2001), "Effects of memory aids on conversations between nursing home residents with dementia and nursing assistants", Neuropsychological Rehabilitation: An International Journal, Vol. 11, No. 3-4, pp. 399-427.

Hughes, J., Bagley, H., Reilly, S., Burns, A. and Challis, D. (2008), "Care staff working with people with dementia: training, knowledge and confidence", Dementia, Vol. 7, No. 2, pp. 227238.

Kitzinger, J. (1995), “Introducing focus groups”, British Medical Journal, Vol. 311, pp. 299302.

Knapp, M., Prince, M., Albanese, E., Banerjee, S., Dhanasiri, S., Fernandez, J.L., Ferri, C., McCrone, P., Snell, T. and Stewart, R. (2007), Dementia UK, PSSRU, London School of Economics and the Institute of Psychiatry, London, for the Alzheimer's Society, London.

Kosloski, K. and Montgomery R. (1993), “The effects of respite on caregivers of Alzheimer's patients: one-year evaluation of the Michigan Model Respite Programs", The Journal of Applied Gerontology, Vol. 12, No. 1, pp. 4-17.

McDonald, A. and Heath, B. (2008), "Developing services for people with dementia: Findings from research in a rural area", Quality in Ageing and Older Adults, Vol. 9, No. 4, pp. 9-18.

Merton, R. and Kendall, P. (1946), “The focused interview”, American Journal of Sociology, Vol. 51, No. 6, pp. 541-557. 
Mossello, E., Caleri, V., Razzi, E., Di Bari, M., Cantini, C., Tonon, E., Lopilato, E., Marini, M., Simoni, D., Cavallini, M., Marchionni, N., Biagini, C. and Masotti, G. (2008), "Day care for older dementia patients: favorable effects on behavioural and psychological symptoms and caregiver stress", International Journal of Geriatric Psychiatry, Vol. 23, No. 10, pp. 1066-72.

Neville, C. and Byrne, G. (2006), "The impact of residential respite care on the behaviour of older people”, International Psychogeriatrics, Vol. 18, No. 1, pp. 163-170.

Newbronner, L., Chamberlain, R., Borthwick, R., Baxter, M. and Glendinning, C. (2013), A Road Less Rocky - Supporting Carers of People with Dementia, Carers Trust, London.

Nieboer, A., Koolman, X. and Stolk, E. (2010), "Preferences for long-term care services: willingness to pay estimates derived from a discrete choice experiment", Social Science and Medicine, Vol. 70, No. 9, pp. 1317-1325.

Nurock, S. and Wojciechowska, M. (2007), "What real outcomes matter to caregivers?", International Psychogeriatrics, Vol. 19, No. 3, pp. 355-362.

Riordan, J. and Bennett, A. (1998), “An evaluation of an augmented domiciliary service to older people with dementia and their carers", Aging and Mental Health, Vol. 2, No. 2, pp. 137143.

Ryan, M., Bate, A., Eastmond, C. and Ludbrook, A. (2001), "Use of discrete choice experiments to elicit preferences", Quality in Health Care, Vol. 10, Suppl I, pp. i55-i60. 
Ryan, M., Netten, A., Skåtun, D. and Smith, P. (2006), "Using discrete choice experiments to estimate a preference-based measure of outcome-an application to social care for older people", Journal of Health Economics, Vol. 25, No. 5, pp. 927-944.

Ryan, M., Gerard, K., and Amaya-Amaya, M. (2008), (eds). Using discrete choice experiments to value health and health care. Springer, New York, NY.

Singh, P., Hussain, R., Khan, A., Irwin, L. and Foskey, R. (2014), “Dementia care: intersecting informal family care and formal care systems", Journal of Aging Research, Vol. 2014, doi:10.1155/2014/486521.

Sloane, N. (2010), A Library of Orthogonal Arrays, http://neilsloane.com/oadir/ [accessed 25/06/2010]

Stirling, C., Dwan, C. and McKenzie, A. (2014), "Why carers use adult day respite: a mixed method case study”, BMC Health Services Research, Vol. 14, doi:10.1186/1472-6963-14-245.

Turner, D., Tarrant, C., Windridge, K., Bryan, S., Boulton, M., Freeman, G. and Baker, R. (2007), "Do patients value continuity of care in general practice? An investigation using stated preference discrete choice experiments", Journal of Health Services Research and Policy, Vol. 12, No. 3, pp. 132-137.

Wilberforce, M., Challis, D., Davies, L., Kelly, MP., Roberts, C., Loynes, N. (2016), “Personcentredness in the care of older adults: a systematic review of questionnaire-based scales and 
their measurement properties." BMC Geriatrics, Vol. 16, No. 63 DOI 10.1186/s12877-0160229-y.

Woodward, C., Abelson, J., Tedford, S. and Hutchison, B. (2004), "What is important to continuity in home care? Perspective of key stakeholders", Social Science and Medicine, Vol. 58, No. 1, pp. 177-192. 
Table I Attributes - description and benefit

\begin{tabular}{|c|c|c|}
\hline Attribute & Description & Benefit \\
\hline $\begin{array}{l}\text { Home care workers } \\
\text { use life story or } \\
\text { memory wallets }\end{array}$ & $\begin{array}{l}\text { A collection of pictures and sentences } \\
\text { to remind the owner of specific people, } \\
\text { places, and events (Bourgeois, 2013). }\end{array}$ & $\begin{array}{l}\text { A means of enhancing conversation between } \\
\text { people with dementia and others including } \\
\text { caregivers (Bourgeois, 2013; Hoerster et al., } \\
2001 \text { ) }\end{array}$ \\
\hline $\begin{array}{l}\text { Home care workers } \\
\text { are available* }\end{array}$ & $\begin{array}{l}\text { Availability of home care workers } \\
\text { during day, night and weekends and } \\
\text { ability to provide care appropriate to } \\
\text { the needs of a person with dementia } \\
\text { (Alzheimer Scotland, 2008). }\end{array}$ & $\begin{array}{l}\text { Enabling older people with dementia to live } \\
\text { at home for longer and promote well-being } \\
\text { of carers in their caring role (Riordan and } \\
\text { Bennett, 1998; Singh et al., 2014). }\end{array}$ \\
\hline $\begin{array}{l}\text { The home care worker } \\
\text { visiting* }\end{array}$ & $\begin{array}{l}\text { Continuity of care through the same } \\
\text { care worker caring for the same person } \\
\text { over time (Challis et al., 2009) }\end{array}$ & $\begin{array}{l}\text { Promotes independence of older person with } \\
\text { dementia and minimises anxiety and } \\
\text { confusion (Bamford and Bruce, 2000; } \\
\text { Newbronner et al., 2013; Woodward et al., } \\
\text { 2004) }\end{array}$ \\
\hline $\begin{array}{l}\text { Respite opportunities } \\
\text { for carers }\end{array}$ & $\begin{array}{l}\text { Short or long-term care provided within } \\
\text { or outside of the home for a few hours } \\
\text { or over longer time periods by home } \\
\text { care providers, nursing homes or day } \\
\text { care centres (Kosloski and } \\
\text { Montgomery, 1993; Singh et al., 2014). }\end{array}$ & $\begin{array}{l}\text { Of benefit both to the carer and the person } \\
\text { they care for ( Kosloski and Montgomery, } \\
\text { 1993; Neville and Byrne, 2006; Mossello et } \\
\text { al, 2008; Singh et al., 2014; Stirling et al., } \\
\text { 2014) }\end{array}$ \\
\hline $\begin{array}{l}\text { Home care workers } \\
\text { have additional } \\
\text { training in dementia } \\
\text { care }\end{array}$ & $\begin{array}{l}\text { Awareness of the needs of people with } \\
\text { dementia and appropriately training } \\
\text { (Newbronner et al., 2013; Singh et al., } \\
\text { 2014) }\end{array}$ & $\begin{array}{l}\text { Demonstrated to have a positive influence on } \\
\text { staff confidence, knowledge and attitudes } \\
\text { regarding people with dementia (Hughes et } \\
\text { al., 2008; Featherstone et al., 2004). }\end{array}$ \\
\hline
\end{tabular}

*consultation meetings identified as most important. 
Table II Discrete choice experiment-attributes and levels

\begin{tabular}{|c|c|c|c|}
\hline Attribute & & Levels & \\
\hline $\begin{array}{l}\text { 1. Home care workers use life story or } \\
\text { memory wallets }^{1}\end{array}$ & Not at all & To some extent & Fully \\
\hline 2. There is a waiting list for this service ${ }^{2}$ & No waiting list & 5 weeks & 10 weeks \\
\hline 3. Home care workers are available ${ }^{1}$ & Day time only Mon-Fri & Night time Mon-Fri also if required & Weekends also if required \\
\hline 4. Respite opportunities for carers ${ }^{1}$ & Not provided & Limited respite service & $\begin{array}{c}\text { Full respite service for weekends and } \\
\text { longer periods }\end{array}$ \\
\hline 5. The home care worker visiting ${ }^{1}$ & Can be a different person each time & Varies from time to time & Is the same person each time \\
\hline 6. The cost of this service is ${ }^{2,3}$ & $£ 140$ per week & $£ 170$ per week & $£ 200$ per week \\
\hline $\begin{array}{l}\text { 7. Home care workers have additional } \\
\text { training in dementia care }\end{array}$ & No training & Some training & Full training \\
\hline
\end{tabular}

1 Attributes coded as dummy variables

${ }^{2}$ Attributes take numerical value

${ }^{3}$ Levels informed by real unit costs of home care in England (Knapp et al., 2007) 


\section{Figure I Example of a choice question}

Question 2

Imagine being offered these options for a home care service for your relative/person for whom you care today and that you had a budget of $£ 230$ per week to pay for care.

Please tick the box for the option you prefer more (A or B)

\begin{tabular}{|l|l|l|}
\cline { 2 - 3 } \multicolumn{1}{l|}{} & Option A & Option B \\
\hline Home care workers use life story or memory wallets & To some extent & Fully \\
\hline There is a waiting list for this service of: & 5 weeks & 10 weeks \\
\hline Home care workers are available: & $\begin{array}{l}\text { Night time Mon-Fri if } \\
\text { required }\end{array}$ & $\begin{array}{l}\text { Weekends if } \\
\text { required }\end{array}$ \\
\hline Respite opportunities for carers & Limited respite service & $\begin{array}{l}\text { Full respite } \\
\text { service for } \\
\text { weekends and } \\
\text { longer periods }\end{array}$ \\
\hline The home care worker visiting: & Varies from time to time & $\begin{array}{l}\text { Is the same } \\
\text { person each time }\end{array}$ \\
\hline The cost of this service is: & $£ 170$ per week & £200 per week \\
\hline Home care workers have additional training in dementia care & No training & Some training \\
\hline
\end{tabular}

Which service do you prefer?

(Tick one) 
Table III Discrete choice experiment - regression analysis ${ }^{1}$

\begin{tabular}{lcc}
\hline \multicolumn{1}{c}{ Attribute } & $\begin{array}{c}\text { Coefficient } \\
(\mathrm{SE})\end{array}$ & p-value \\
\hline $\begin{array}{l}\text { Home care workers use life story or memory } \\
\text { wallets }\end{array}$ & & \\
$\quad$ (Not at all) & & \\
To some extent & $0.149(0.139)$ & 0.287 \\
$\quad$ Fully & $0.263(0.138)$ & 0.056
\end{tabular}

Home care workers are available

(Day time only Mon-Fri)

Night time Mon-Fri also if required

$0.105(0.139) \quad 0.451$

Weekends also if required

$0.314(0.138) \quad 0.023$

Respite opportunities for carers

(Not provided)

Limited respite service

$0.357(0.139) \quad 0.010$

Full respite service for weekends and longer periods

$0.468(0.138) \quad 0.001$

The home care worker visiting

(Can be a different person each time)

Varies from time to time

$0.245(0.141) \quad 0.081$

Is the same person each time

$0.696(0.138) \quad 0.000$

Home care workers have additional training in dementia care

(No training)

Some training

$0.650(0.142) \quad 0.000$

Full training

$0.661(0.137) \quad 0.000$

Cost of service

$0.003(0.002) \quad 0.210$

Waiting time for service

$-0.016(0.014) \quad 0.240$

Pseudo $\mathrm{R}^{2}$

0.12

Log-likelihood

$-305.308$

No. of observations

1000

No. of individuals

28

${ }_{1}$ The functional form of the model is: $\mathrm{V}=\beta 1$ wallet $+\beta 2$ availability $+\beta 3$ respite $+\beta 4$ home care worker $+\beta 5$ training + $\beta 6$ waiting time $+\beta 7 \operatorname{cost}$, where $\mathrm{V}=$ the utility of a given home care package compared to an alternative. It is a linear model and we assume it is additive, so that each coefficient represents the part-worth or utility of the attribute (level) and the total value of home care equals the sum of the coefficients. Each level is compared to the base level given in brackets. 
